\title{
Correlated Evolution of Short Wavelength Sensitive Photoreceptor Sensitivity and Color Pattern in Lake Malawi Cichlids
}

\section{OPEN ACCESS}

Edited by:

Wayne Iwan Lee Davies, University of Western Australia,

Australia

Reviewed by:

Mark S. Springer, University of California, Riverside, USA

Russell Fernald,

Stanford University, USA

*Correspondence:

Michael J. Pauers

mjpauers@gmail.com;

Jay Neitz

jneitz@uw.edu

Specialty section:

This article was submitted to Behavioral and Evolutionary Ecology,

a section of the journal

Frontiers in Ecology and Evolution

Received: 26 November 2015 Accepted: 02 February 2016

Published: 23 February 2016

Citation:

Pauers MJ, Kuchenbecker JA, Joneson SL and Neitz J (2016)

Correlated Evolution of Short Wavelength Sensitive Photoreceptor Sensitivity and Color Pattern in Lake Malawi Cichlids.

Front. Ecol. Evol. 4:12. doi: 10.3389/fevo.2016.00012

\begin{abstract}
Michael J. Pauers 1, 2,3*, James A. Kuchenbecker ${ }^{4}$, Suzanne L. Joneson ${ }^{2}$ and Jay Neitz ${ }^{4 *}$
${ }^{1}$ Division of Fishes, Section of Vertebrate Zoology, Milwaukee Public Museum, Milwaukee, WI, USA, ${ }^{2}$ Department of Biological Sciences, University of Wisconsin - Waukesha, Waukesha, WI, USA, ${ }^{3}$ School of Freshwater Sciences, University of Wisconsin - Milwaukee, Milwaukee, WI, USA, ${ }^{4}$ Department of Ophthalmology, University of Washington, Seattle, WA, USA
\end{abstract}

For evolutionary ecologists, the "holy grail" of visual ecology is to establish an unambiguous link between photoreceptor sensitivity, the spectral environment, and the perception of specific visual stimuli (e.g., mates, food, predators, etc.). Due to the bright nuptial colors of the males, and the role female mate choice plays in their evolution, the haplochromine cichlid fishes of the African great lakes are favorite research subjects for such investigations. Despite this attention, current evidence is equivocal; while distinct correlations among photoreceptor sensitivity, photic environment, and male coloration exist in Lake Victorian haplochromines, attempts to find such correlations in Lake Malawian cichlids have failed. Lake Malawi haplochromines have a wide variability in their short-wavelength-sensitive photoreceptors, especially compared to their mid- and long-wavelength-sensitive photoreceptors; these cichlids also vary in the degree to which they express one of three basic color patterns (vertical bars, horizontal stripes, and solid patches of colors), each of which is likely used in a different form of communication. Thus, we hypothesize that, in these fishes, spectral sensitivity and color pattern have evolved in a correlated fashion to maximize visual communication; specifically, ultraviolet sensitivity should be found in vertically-barred species to promote "private" communication, while striped species should be less likely to have ultraviolet sensitivity, since their color pattern carries "public" information. Using phylogenetic independent contrasts, we found that barred species had strong sensitivity to ultraviolet wavelengths, but that striped species typically lacked sensitivity to ultraviolet light. Further, the only variable, even when environmental variables were simultaneously considered, that could predict ultraviolet sensitivity was color pattern. We also found that, using models of correlated evolution, color pattern and ultraviolet sensitivity are correlated in Lake Malawi cichlid evolution, with the likely ancestor being a vertically-barred, ultraviolet-sensitive species, the descendants of which lost both ultraviolet sensitivity and a barred color pattern. These results, indicating that communication of "public" and "private" signals is mediated via differing perceptions of color patterns, suggest a functional connection between visual sensitivity and color pattern, a novel finding in Lake Malawi cichlids.

Keywords: Lake Malawi, cichlids, visual ecology, ultraviolet photoreception, correlated evolution, phylogenetic independent contrasts 


\section{INTRODUCTION}

For those who study the ecology of vision, the "holy grail" of such studies is to discover an unambiguous link among photoreceptor sensitivity, the wavelengths of light available within the study organism's habitat, and the perception of ecologically relevant visual stimuli, such as food, predators, or mates (Ryan and Rand, 1990; Endler, 1992; van Staaden and Smith, 2011). This is, of course, a convenient "shorthand" view of how vision works in animals, one that overlooks the complex relationships and interactions among photons, opsins, neurons, and the resulting image constructed by the organism's brain (Endler, 1990, 1991; Fernald, 2006). Nonetheless, organisms do face fitness consequences if they fail to detect photons in the proper context (Endler, 1978, 1992; Milner and Goodale, 1995; Land and Nilsson, 2002), so this kind of proximate approach to studying the perception of light is valuable as a first step toward understanding the role color vision plays in ecological circumstances (Endler, 1978, 1990; Endler and Mielke, 2005).

The cichlid fishes of the African great lakes have received much attention from visual ecologists; the bright colors of the males, as well as the presence and importance of visually-based female mate choice, strongly suggest a history of correlated evolution between nuptial coloration and visual sensitivity. While such a connection has been shown in Lake Victorian cichlids (Seehausen et al., 2008), this has not been as clearly demonstrated in the Lake Malawi cichlids. In the most comprehensive such study on Malawian cichlids, Dalton et al. (2010) fail to find any correlation among sensitivity, photic environment, and coloration; indeed, they found that depth does not influence the perceptibility of cichlid hues, suggesting that depth may not have an influence on photoreceptor sensitivity.

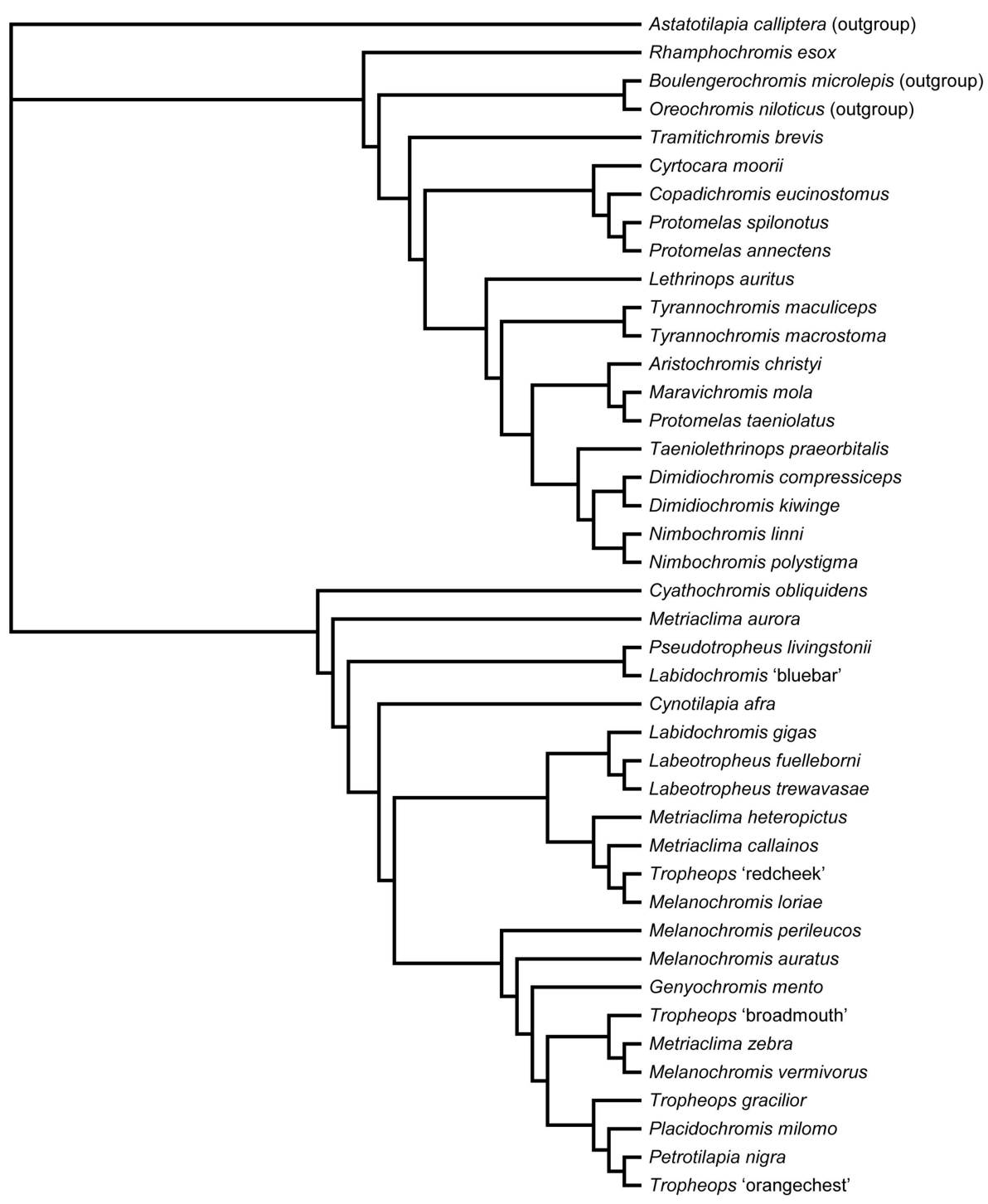

FIGURE 1 | Maximum Likelihood phylogeny of Lake Malawi cichlids based on the ND2 mitochondrial gene. 
Within the past 15 years, the existence of ultraviolet (UV) vision in fishes has also attracted the attention of visual ecologists (Losey et al., 1999). While initially thought rare, due in part to the rapid attenuation of UV wavelengths in water, many fishes have UV-sensitive photopigments or UV-reflective color patterns (Losey et al., 2003; Marshall et al., 2003; Jordan et al., 2004a; Siebeck et al., 2010). In fishes, UV vision is known to aid foraging (Browman et al., 1994), species recognition (Cheney and Marshall, 2009; Siebeck et al., 2010), and mate choice Kodric-Brown and Johnson, 2002). The role of UV vision in fish communication is particularly interesting because it is often used as a "private" means of communication; i.e., a range of wavelengths visible to conspecifics, but not to other species, especially predators (Endler, 1992; Cummings et al., 2003).

In Lake Malawi cichlids, there is wide variability in the peak sensitivities of short wavelength sensitive (SWS) photopigments. Some species have UV-sensitive SWS photopigments, while others are violet- or blue-sensitive (Parry et al., 2005). Some of the rock-dwelling species ("mbuna") use their UV sensitivity to aid foraging (Jordan et al., 2004b), and many species have UV-reflective color patterns (Jordan et al., 2004a; Pauers et al., 2004; Parry et al., 2005), though the use of UV vision or UV-reflective color patterns in communication has not been explicitly demonstrated. This variability in SWS sensitivity is in stark contrast to the much smaller variation among the peak sensitivities of the longer wavelength-sensitive photopigments within these same species; the peak sensitivity of the SWS photopigment ranges from 360 to $433 \mathrm{~nm}$, while the peak sensitivity of the longer-wavelength sensitive photopigments ranges from 499 to $548 \mathrm{~nm}$ (Parry et al., 2005; Dalton et al., 2010). This relatively broad range in SWS sensitivity strongly suggests that there must be a function associated with the difference in UV- vs. violet- or blue-sensitive SWS photopigments.

Lake Malawi cichlids also display marked differences in their gross color patterns. Many species display vertical bars as a major component of their color patterns, and horizontal stripes are also common (Seehausen et al., 1999). Horizontal stripes are well-understood to be used as camouflage, especially by piscivorous cichlids, but the function of bars, on the other hand, seems related to promoting crypsis in a highly structured habitat (Seehausen et al., 1999). A third color pattern common to Lake Malawi cichlids consists of solid patches of contrasting colors. Interestingly, these "solid" patterns are likely to evolve under conditions similar to those that promote the evolution of vertical bars (Kenward et al., 2004), but are also likely to have evolved in these fishes for the purpose of mate attraction (Seehausen et al., 1999).

No matter the type of gross color pattern present, species that use these patterns to be conspicuous to conspecifics would have a selective advantage if they were simultaneously cryptic to their predators (Endler, 1992; Cummings et al., 2003). Further, predatory fishes would also have a selective advantage if their camouflage markings were visible to their prey, no matter the visual sensitivity of the observer. Thus, we suggest that in Lake Malawi cichlids, SWS sensitivity and color pattern have coevolved to create "private" and "public" bands of
TABLE 1 | Species used in phylogenetic analyses and GenBank accession numbers for ND2 sequences.

\begin{tabular}{|c|c|}
\hline Species & Accession number \\
\hline Aristochromis christyi & EF585282 \\
\hline Copadichromis eucinostomus & EF585268 \\
\hline Cyathochromis obliquidens & GQ422579 \\
\hline Cynotilapia afra & EF585264 \\
\hline Cyrtocara moorii & AY930089 \\
\hline Dimidiochromis compressiceps & EF585267 \\
\hline Dimidiochromis kiwingi & GU946222 \\
\hline Genyochromis mento & AF305297 \\
\hline Labeotropheus fuelleborni & EF585259 \\
\hline Labeotropheus trewavasae & GU946225 \\
\hline Labidochromis 'bluebar' & GQ422573 \\
\hline Labidochromis gigas & EF585276 \\
\hline Lethrinops auritus & U07252 \\
\hline Maravichromis mola & EF585274 \\
\hline Melanochromis auratus & AY930069 \\
\hline Melanochromis perileucos & GQ422574 \\
\hline Melanochromis loriae & JX119227 \\
\hline Melanochromis vermivorous & EF585270 \\
\hline Metriaclima aurora & EF585266 \\
\hline Metriaclima callainos & EF585271 \\
\hline Metriaclima heteropictus & GQ422584 \\
\hline Metriaclima zebra & DQ093114 \\
\hline Nimbochromis linni & EF585279 \\
\hline Nimbochromis polystigma & EF585262 \\
\hline Petrotilapia nigra & EU661721 \\
\hline Placidochromis milomo & GQ422590 \\
\hline Protomelas annectens & EU661718 \\
\hline Protomelas spilonotus & EF585253 \\
\hline Protomelas taeniolatus & GU946232 \\
\hline Pseudotropheus livingstonii & EF585273 \\
\hline Rhamphochromis esox & GU946233 \\
\hline Taeniolethrinops praeorbitalis & GU946236 \\
\hline Tramitochromis brevis & AF305320 \\
\hline Tropheops "broadmouth" & GQ422589 \\
\hline Tropheops gracilior & EF585260 \\
\hline Tropheops "orangechest" & GQ422583 \\
\hline Tropheops "redcheek" & GQ422568 \\
\hline Tyrannochromis macrostoma & EF585257 \\
\hline Tyrannochromis maculiceps & GQ422571 \\
\hline \multicolumn{2}{|l|}{ Outgroups } \\
\hline Astatotilapia calliptera & GU946219 \\
\hline Boulengerochromis microlepis & AF317229 \\
\hline Oreochromis niloticus & AF317237 \\
\hline
\end{tabular}

communication. Specifically, we hypothesize that cichlids with UV sensitivity are more likely to have color patterns featuring vertical bars, since both are likely components of "private," cryptic signals. Conversely, predatory fish, which rely on clear, obvious camouflage, are more likely to have color patterns with horizontal stripes, and less likely to need "privacy" for this signal, and are thus likely to lack UV-sensitive SWS photoreceptors. 


\section{MATERIALS AND METHODS}

\section{Malawi Cichlid Color Pattern, Photoreceptor Sensitivity, and Ecological Data}

Data were compiled regarding photopigment sensitivities (Hofmann et al., 2009); male nuptial color patterns (Ribbink et al., 1983; Konings, 2007); diet (Hofmann et al., 2009; Konings and Stauffer, 2012), depth (Ribbink et al., 1983); and the wavelength of the radiance spectra about which quanta are likely to be most abundant ( $\lambda$ P50) at two locations in Lake Malawi, Otter Point and Thumbi West (Sabbah et al., 2011). Regarding photopigment sensitivities, Hofmann et al., 2009) report two values: the peak sensitivity of the SWS opsin found in the single cones, but only the stronger of the two sensitivities recorded for the two opsins found in the double cones; we use both values as reported, with the understanding that we are missing information about the way the double-cone system discriminates among wavelengths (Neitz and Neitz, 2011). Using Seehausen et al. (1999) and Konings (2007) as guides, color patterns were classified as barred, striped, or solid. Colors comprising $\geq 50 \%$ of the body were considered the main hue of the fish, and all longwavelength colors (e.g., yellows, oranges, and reds) were classified as "carotenoid" colors. Maximum depths of most species $(n=$

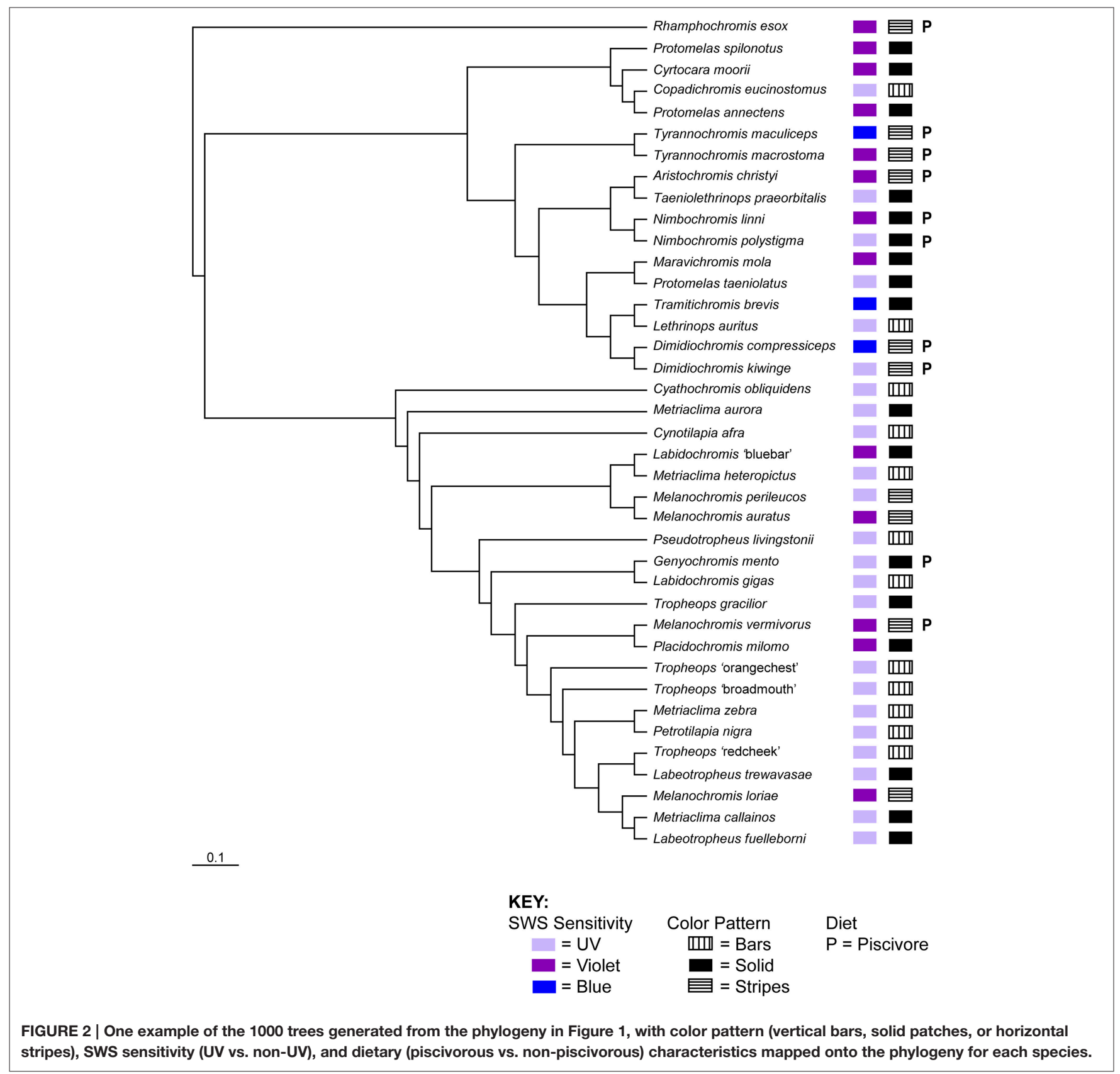




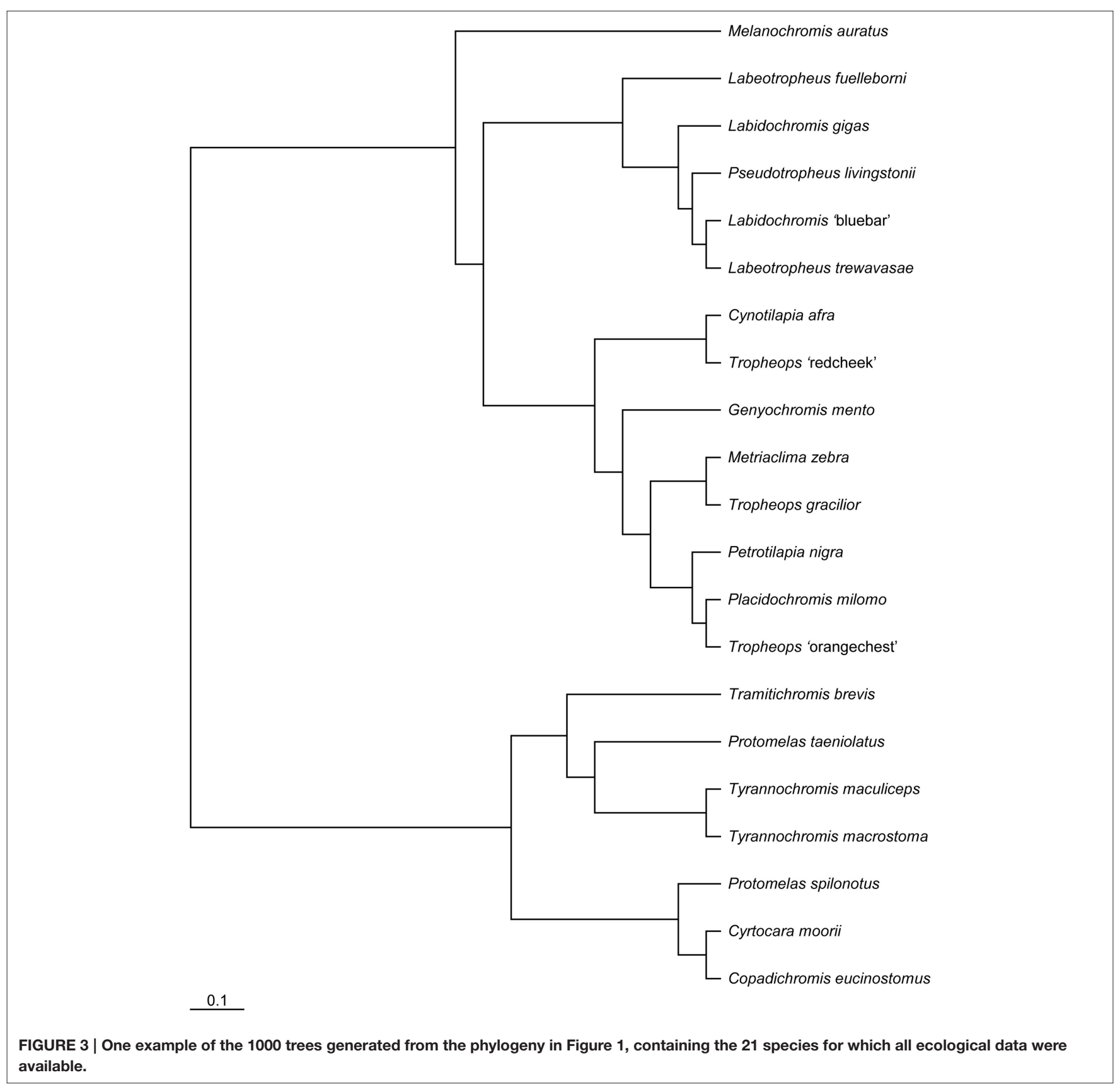

27) were obtained from Ribbink et al. (1983). The $\lambda$ P50 of the sidewelling radiance spectra was used to represent spectral habitats, as radiance spectra include radiant, reflective, and transmissive sources (Endler, 1993). The $\lambda$ P50 at the maximum depth of each species were estimated from Sabbah et al. (2011); because these authors recorded spectral data at discrete depths (at $1,3,5,6,9,12$, and $15 \mathrm{~m}$ of depth) that did not always match the distributions reported by Ribbink et al. (1983), the $\lambda$ P50 of the next deepest depth was used (e.g., a species with a maximum depth of $10 \mathrm{~m}$ was assigned the $\lambda$ P50 at $12 \mathrm{~m}$ ). Further, species with maximum depths $\geq 15 \mathrm{~m}(n=13)$ were assigned the $\lambda$ P50 of $15 \mathrm{~m}$.

\section{Phylogenetic Independent Contrasts}

We used RAxML (Stamatikis, 2014) to generate a ML tree (Figure 1) using sequences of the mitochondrial ND2 gene downloaded from GenBank (Table 1). First, these sequences were aligned using T-Coffee (Notredame et al., 2000), and we then removed poorly aligned regions using stringent conditions in Gblocks (Castresana, 2000). Using the GTRGAMMA model of molecular evolution, we generated support values using 1000 pseudoreplicates. These 1000 trees were then imported into the ape package (Paradis et al., 2015) in $R$, and we began by pruning all outgroups (Figure 2). We then calculated a phylogenetic independent contrast between the peak sensitivities of the SWS 
TABLE 2 | Phylogenetic Independent Contrast between opsin peak sensitivity and color pattern.

\begin{tabular}{|c|c|c|c|c|c|}
\hline \multicolumn{6}{|c|}{ (A) SWS PEAK SENSITIVITY } \\
\hline \multirow[t]{2}{*}{ Residuals } & Minimum & 1st Quartile & Median & 3rd Quartile & Maximum \\
\hline & -155.430 & -52.920 & -24.410 & 54.500 & 262.370 \\
\hline Coefficients & Estimate & Std. Error & t-value & $\operatorname{Pr}(>|t|)$ & \\
\hline Color pattern & 31.150 & 6.421 & 4.851 & 0.00002 & \\
\hline \multicolumn{6}{|c|}{ Residual standard error: 87.91 on 36 degrees of freedom } \\
\hline \multicolumn{6}{|c|}{ Multiple $R^{2}=0.395$, Adj. $R^{2}=0.379$} \\
\hline \multicolumn{6}{|c|}{$F_{(1,36)}=23.530, p=0.00002$} \\
\hline \multicolumn{6}{|c|}{ Pairwise Comparisons; $p$-values Holm corrected } \\
\hline & Bars & Solid & & & \\
\hline Solid & 0.02907 & - & & & \\
\hline Stripes & 0.00032 & 0.02907 & & & \\
\hline \multicolumn{6}{|c|}{ (B) DOUBLE CONE PEAK SENSITIVITY } \\
\hline \multirow[t]{2}{*}{ Residuals } & Minimum & 1st Quartile & Median & 3rd Quartile & Maximum \\
\hline & -139.603 & -15.460 & 5.923 & 17.916 & 125.287 \\
\hline Coefficients & Estimate & Std. Error & $t$-value & $\operatorname{Pr}(>|t|)$ & \\
\hline Color pattern & -1.182 & 3.264 & -0.362 & 0.926 & \\
\hline \multicolumn{6}{|c|}{ Residual standard error: 44.68 on 36 degrees of freedom } \\
\hline \multicolumn{6}{|c|}{ Multiple $R^{2}=0.0003$, Adj. $R^{2}=-0.024$} \\
\hline \multicolumn{6}{|c|}{$F_{(1,36)}=0.131, p=0.719$} \\
\hline \multicolumn{6}{|c|}{ Pairwise Comparisons; $p$-values Holm corrected } \\
\hline & Bars & Solid & & & \\
\hline Solid & 1.00 & - & & & \\
\hline Stripes & 1.00 & 1.00 & & & \\
\hline
\end{tabular}

photoreceptors and color pattern of all species in the dataset $(n=39)$. We then pruned the phylogeny again, leaving only those species for which we had a complete set of photoreceptor sensitivity and ecological data (Figure 3; $n=21$ ). Using this pruned phylogeny, two phylogenetic independent ANOVAs were calculated. In the first, SWS peak sensitivity was the dependent variable, and color pattern, diet, maximum depth, irradiance, and body color were independent variables; in the second, the double cone peak sensitivity was used as the dependent variable, with the same set of independent variables.

\section{Correlated Trait Evolution}

Following the methodology of Kelley et al. (2013), we attempted to determine whether or not visual sensitivity and color pattern have evolved in a correlated fashion in Lake Malawi cichlids. To begin, we used the geiger package (Harmon et al., 2014) in $R$ to calculate $\lambda$, an estimate of phylogenetic signal (Pagel, 1999), for both visual sensitivity and color pattern. We modified the phylogeny described above (e.g., outgroups removed and all 39 species of Malawian cichlids included) to create two new trees, one in which branch lengths were set to $\lambda=0$, indicating no phylogenetic signal; and another in which the branch lengths were set to $\lambda=1$, indicative of a random, Brownian motion of traits. The fit of these models was compared to that of the original phylogeny using likelihood ratio (LR) tests.

We then generated another $\mathrm{ML}$ tree from the original ND2 sequence data, and generated support values using 1000 pseudoreplicates using the GTRGAMMA model of molecular evolution. We then used these 1000 trees in our analyses of correlated trait evolution. To simplify these analyses, we recoded our traits as discrete, binary traits. For visual sensitivity, we classified fish as either UV sensitive (e.g., SWS peak sensitivity < $400 \mathrm{~nm}$ ) or non-UV (SWS peak sensitivity $\geq 400 \mathrm{~nm}$ ). For color pattern, we had to simplify our three classes (bars, solid, and stripes) into two, bars and stripes. To do this, we examined photographs of juvenile, female, and immature/subordinate males (using Konings, 2007), in order to better distinguish the underlying melanin patterns of solid-colored fishes; even in species in which dominant, territorial males prominently display solid patches of color, other life history stages display a fundamental melanin-based pattern of vertical bars or horizontal stripes (c.f., Baerends and Baerends-van Roon, 1950; Voss, 1980; Seehausen et al., 1999). Thus, we were able to reclassify solidcolored fishes as either having stripes (e.g., Nimbochromis) or bars (e.g., Labeotropheus).

The 1000 trees and the data matrix of binary visual sensitivity and binary color patterns were imported into BayesTraits (Meade and Pagel, 2014). We used the maximum likelihood (ML) model of evolution to compare both independent (i.e., a model in which discrete character states are assumed to evolve independently) and dependent (i.e., a model in which the evolution of one character depends upon the evolution of the other) models of character evolution.

We originally assumed that, based on O'Quin et al. (2010), a non-UV-sensitive, striped cichlid was the ancestor of the extant Lake Malawi flock. As such, we coded both a lack of UV 
sensitivity and a striped color pattern as 0 s in our data matrix, while UV sensitivity and a barred color pattern were coded as derived traits and were assigned values of 1 . We then used the ML models in BayesTraits to evaluate likely ancestral states by running the dependent and independent models in three ways: "unfossilized" (that is, with no a priori information given to the program regarding ancestral state), "fossilized" at state 0,0 (i.e., fixing stripes and non-UV visual sensitivity as the likely ancestral states), and "fossilized" at state 1,1 (i.e., bars and UVsensitivity as the likely ancestral state). We then compared these models using LR tests. Finally, we investigated the direction of significant evolutionary transitions by sequentially restricting all eight possible changes in character state of the preferred (as indicated by the LR test) model to zero and comparing these to the original, "unfossilized" model.

\section{Photography and Spectrophotometry}

The methods used in this study have been described in detail in Pauers et al. (2004) and are only summarized here. The fish were anesthetized with a weak dose of MS-222 and then placed in an ice bath. Upon removal from the ice bath, the fish was

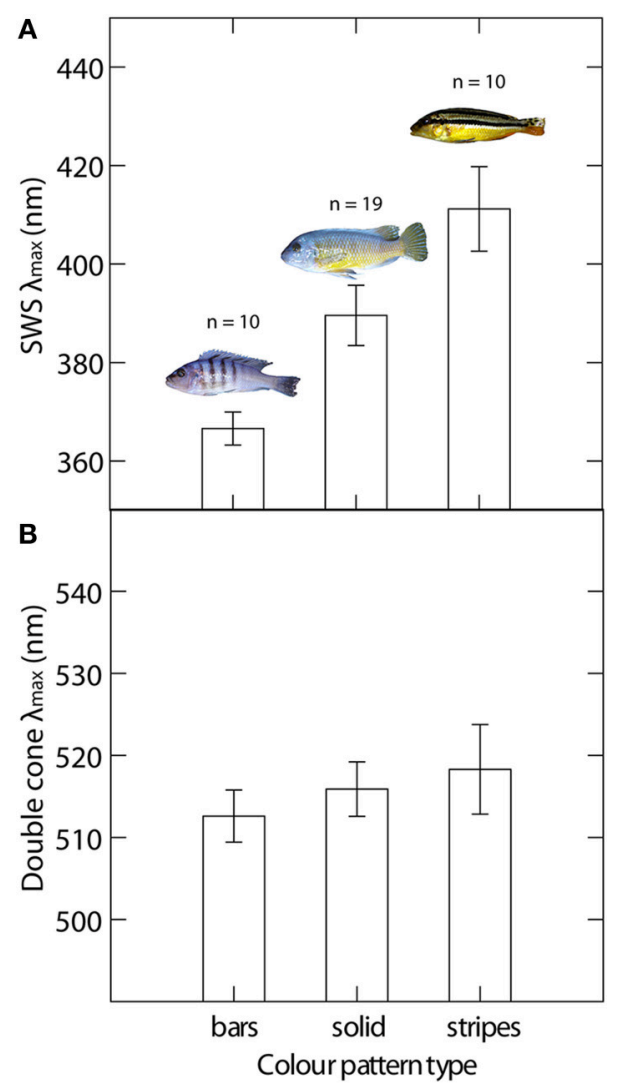

FIGURE 4 | The relationship between color pattern and photoreceptor sensitivity of Lake Malawi cichlids. (A) SWS photoreceptor sensitivity; (B) double cone maximal sensitivity. Inset pictures show examples of each color pattern type (bars, Metriaclima zebra; solid, Labeotropheus c.f. fuelleborni

"Katale"; stripes, Melanochromis auratus). Error bars = standard error. placed on a black cloth and illuminated from its dorsal surface with a Newport $100 \mathrm{~W}$ ozone-free xenon lamp, a $385 \mathrm{~nm}$ LED flashlight, and a $15 \mathrm{~W}$ blacklight. Using a quartz lens attached to an Oriel Instaspec IV CCD, measurements of reflected wavelengths were taken at two points on the fish; these two points were chosen after examining the shapes of reflectance spectra from several other points to represent regions of high contrast within each species' color pattern. After these measurements, the fish was also photographed under both full spectrum and UV only illumination. The spectral data were converted to actual reflectances by dividing them by measurements taken from a Spectralon white standard. The reflectances were then used to calculate quantal catches for each type of photoreceptor in typical ultraviolet- (e.g., peak sensitivities $=368,488,533 \mathrm{~nm}$ ) and violet- (e.g., peak sensitivities $=410,482,529 \mathrm{~nm}$ ) sensitive visual systems. In order to display the differences in sensitivity between these visual systems, the quantal catches of each photoreceptor found in both the model ultraviolet- and violet-sensitive visual systems were plotted against reflected wavelengths.

These methods strictly followed the Guidelines for the Use of Animals in Research published by the Association for the Study of Animal Behaviour and the Animal Behavior Society, and were approved by the University of Wisconsin Colleges Animal Care Committee (protocol \# 1020143) and were additionally approved by the senior staff of the Milwaukee Public Museum (protocol on file with Dr. Ellen J. Censky and available upon request).

\section{RESULTS}

\section{Phylogenetic Independent Contrasts}

Species with a barred color pattern have the shortest SWS photoreceptor peak sensitivity, while those with horizontal stripes have the longest, and solid-colored species have intermediate sensitivities $\left[F_{(1,36)}=25.53, p<0.0001\right.$; Table 2A, Figure $4 \mathrm{~A}]$. There is no such relationship between color pattern and the peak sensitivity of the double cone in cichlid retinae. While striped fish have the longest double cone peak sensitivity, and barred species the shortest, this difference is non-significant $\left[F_{(1,36)}=0.1312, p=0.719\right.$; Table 2B, Figure 4B $]$.

The ANOVA results indicate that of the five independent variables, only color pattern predicts the peak sensitivity of the SWS photoreceptor expressed in the single cones of cichlid retinae (Table $\mathbf{3 A}$ ). The effects of body color, maximum depth, radiance at maximum depth, and habitat type are all nonsignificant. In the case of the double cone photopigments, none of the variables, including pattern, predict peak sensitivity (Table 3B).

\section{Correlated Trait Evolution}

The value of $\lambda$ calculated for color pattern was significantly different from zero, but not from one, suggesting that evolutionary changes in color pattern occur gradually. Visual sensitivity, on the other hand, was found not to be significantly different from either zero or one, suggesting that the evolution of visual systems in these fishes is neither purely phylogenetic nor entirely random (Table 4). 
TABLE 3 | Phylogenetic Independent Contrasts performed on both (A) SWS opsin peak sensitivity and (B) double cone opsin peak sensitivity vs. environmental and color pattern characteristics.

\begin{tabular}{|c|c|c|c|c|c|}
\hline \multicolumn{6}{|c|}{ (A) MODEL 1. SWS PEAK SENSITIVITY } \\
\hline \multirow[t]{2}{*}{ Residuals } & Minimum & 1st Quartile & Median & 3rd Quartile & Maximum \\
\hline & -161.314 & -23.625 & 3.578 & 34.990 & 154.906 \\
\hline Coefficients & Estimate & Std. Error & $t$-value & $p(>|t|)$ & \\
\hline Color pattern & 25.314 & 10.211 & 2.479 & 0.0255 & \\
\hline Diet & -18.095 & 34.768 & -0.520 & 0.6103 & \\
\hline Maximum depth & -0.232 & 0.351 & -0.661 & 0.5184 & \\
\hline Irradiance at maximum depth & -2.095 & 1.018 & -2.059 & 0.0573 & \\
\hline Body color & 4.044 & 17.263 & 0.234 & 0.8180 & \\
\hline \multicolumn{6}{|c|}{ Residual standard error: 85.36 on 15 degrees of freedom } \\
\hline \multicolumn{6}{|c|}{ Multiple $R^{2}=0.5091$, Adj. $R^{2}=0.3455$} \\
\hline \multicolumn{6}{|c|}{$F_{(5,15)}=3.112, p=0.0401$} \\
\hline \multicolumn{6}{|c|}{ (B) MODEL 2. DOUBLE CONE PEAK SENSITIVITY } \\
\hline \multirow[t]{2}{*}{ Residuals } & Minimum & 1st Quartile & Median & 3rd Quartile & Maximum \\
\hline & -109.251 & -23.078 & 2.589 & 16.460 & 43.273 \\
\hline Coefficients & Estimate & Std. Error & $t$-value & $p(>|t|)$ & \\
\hline Color pattern & 8.0873 & 4.7440 & 1.705 & 0.109 & \\
\hline Diet & -1.5978 & 16.1532 & -0.099 & 0.923 & \\
\hline Maximum depth & -0.2151 & 0.1631 & -1.319 & 0.207 & \\
\hline Irradiance at maximum depth & -0.0459 & 0.4727 & -0.097 & 0.924 & \\
\hline Body color & -0.7253 & 8.0206 & -0.090 & 0.929 & \\
\hline \multicolumn{6}{|c|}{ Residual standard error: 39.66 on 15 degrees of freedom } \\
\hline \multicolumn{6}{|c|}{ Multiple $R^{2}=0.2591$, Adj. $R^{2}=0.0122$} \\
\hline$F_{(5,15)}=1.049, p=0.4255$ & & & & & \\
\hline
\end{tabular}

TABLE 4 | Estimates of phylogenetic signal $(\lambda)$ between simplified color pattern (e.g., stripes vs. bars) and visual system (e.g., UV and non-UV).

\begin{tabular}{|c|c|c|c|c|c|c|}
\hline Trait & $\lambda$ & $\operatorname{LL} \lambda$ & LL $\lambda=0$ & $p$ & LL $\lambda=1$ & $p$ \\
\hline Color pattern & 0.544 & -24.31 & -27.03 & 0.02 & -23.53 & 0.21 \\
\hline Visual system & 0.448 & -26.09 & -26.46 & 0.39 & -25.99 & 0.66 \\
\hline
\end{tabular}

LL, log likelihood.

There was a significant difference between the dependent and independent models of trait evolution, and the dependent model was favored by our analyses, having a much lower BIC than the independent model (Table 5). Additionally, since this model indicated that the likely ancestral state was a UV-sensitive fish with a barred color pattern, we reran the dependent model two different ways: One in which a UV-sensitive, barred fish was the ancestor; and one in which a non-UV-sensitive, horizontallystriped fish was the ancestor. All three of these models had very similar log-likelihoods, so the differences among them, based on LR, were not significant (data not shown), but since the original, "unfossilized" model had the most favorable BIC, that is the most likely (Table 5).

The eight possible transitions among the four possible pairs of visual and color pattern characteristics are shown in Figure 5. Of these eight possible transitions, only rates q34 (the transition from vertical bars to horizontal stripes in UV sensitive fish) and q31 (the loss of UV sensitivity in striped fish) are statistically significant. These results further support the possibility that the ancestor of the Lake Malawi cichlid radiation had a UV-sensitive visual system.

\section{Perception of Color Patterns by UV-Sensitive and Non-UV Visual Systems}

To better illustrate how different cichlid visual systems would perceive different color patterns, we present the spectrophotometric data and quantal catches of representative barred, solid, and striped species in Figures 6-11. Two barred species, Metriaclima zebra and Pseudotropheus flavus, are shown in Figures 6, 7, respectively. The quantal catches of these species, both of which are taken from a black bar marking, as well as the respective background color, are greatly different between UV- and violet-sensitive species. While a UV-sensitive species would detect a great deal of contrast between these patches, a non-UV-sensitive species would not (Figures 6C,D, 7C,D). Striped species, represented by Dimidiochromis compressiceps (Figure 8) and Melanochromis auratus (Figure 9), on the other 
TABLE 5 | Model selection based on likelihood ratio tests and Bayesian Information Criteria (BIC).

\begin{tabular}{|c|c|c|}
\hline Model & Log Likelihood & BIC \\
\hline Independent, complete model & -50.565 & 45.868 \\
\hline Dependent, complete model & -44.335 & -21.854 \\
\hline \multicolumn{3}{|c|}{ Likelihood ratio test between the above models: $9.848_{1 d f}, p=0.002$} \\
\hline Dependent, fossilized at 0,0 (non-UV, striped ancestor) & -45.833 & -18.858 \\
\hline \multicolumn{3}{|c|}{ Likelihood ratio test: Dependent, complete vs. Dependent, 0,0 models: $2.995_{1 d f}, p=0.080$} \\
\hline Dependent, fossilized at 1,1 (UV, barred ancestor) & -45.505 & -19.514 \\
\hline Likelihood ratio test: Dependent, complete vs. Depende & & \\
\hline
\end{tabular}

The preferred model will have the lowest value for the BIC.

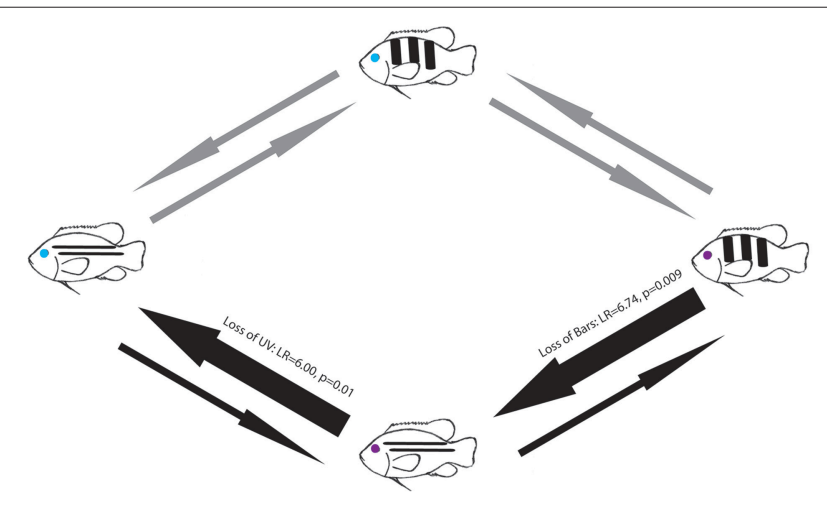

FIGURE 5 | Evolutionary transitions among SWS sensitivity and color pattern character states in Lake Malawi cichlids. Black arrows: likely transitions; statistically significant transitions are indicated by the thick arrows and $p$-values indicated above arrows. Gray arrows: highly unlikely transitions. Violet eyes: UV-sensitive; blue eyes: non-UV-sensitive. Notice that the likely ancestral state of the Lake Malawi cichlids is a UV-sensitive, barred species, descendants of which would subsequently lose both a barred color pattern and UV sensitivity during the radiation of these fishes.

hand, would likely appear the same to either type of visual system, as indicated by the closely overlapping quantal catches in Figures 8C,D, 9C,D.

The solid-colored species, Labeotropheus c.f. fuelleborni "Katale" and Iodotropheus sprengerae, have a surprising amount of ultraviolet reflectivity, especially in their carotenoid-based colors (Figures 10A, 11A, respectively). As such, the major difference between how UV- and non-UV-sensitive species would perceive these patterns would likely be in the amount of contrast between the patches we selected for analysis.

To simulate how a UV-sensitive visual system would perceive the colors of the fishes detailed above, we offer Figure 12 as a heuristic. In the left column of this figure are pictures of each species taken under full-spectrum lighting, while the right column has photographs of the same individuals taken moments later under UV light. As predicted by our hypothesis, the patterns of barred and solid-patterned species look quite different under UV illumination, while those with horizontal stripes look very similar no matter the illuminant.

\section{DISCUSSION}

There is some evidence indicating that differently-tuned SWS opsins serve different functions in fishes. For example, among coral reef fishes, UV-sensitive visual systems are important in species recognition (Côté and Cheney, 2005; Cheney and Marshall, 2009; Siebeck et al., 2010), and are particularly sensitive to species-specific within-color pattern contrast (Losey, 2003; Siebeck et al., 2010); also, UV-sensitive species are better able to discriminate between helpful "cleaner" species and their harmful mimics, largely due to distinctive UV reflectivity in the mimics' color patterns (Côté and Cheney, 2005; Cheney and Marshall, 2009). Lake Malawi cichlids have been documented to use particular color patterns for communication (Pauers et al., 2012); however, our results are the first demonstration of a relationship between gross color pattern and photoreceptor sensitivity. Species with barred patterns have SWS peak sensitivity values at wavelengths that are shorter than either of the other patterns; indeed, these sensitivities tend to fall in the UV spectrum. Further, only color pattern type could successfully predict SWS peak sensitivity; no other variable, including depth and irradiance, had statistically significant relationships with SWS sensitivity. Most interestingly, our results indicate that visual sensitivity and color pattern did evolve in a correlated fashion; the ancestral cichlid was likely a UV sensitive fish with a barred color pattern that first changed its pattern from barred to striped, followed by a loss of UV sensitivity.

The peak sensitivity of the mid/long wavelength sensitive double cone was not correlated with color pattern type among species, nor did any variable successfully predict the peak sensitivity of this photoreceptor. Further, double cone peak sensitivity varied little across all species, so these fishes are all receiving similar information with these cones. While the double cone system may provide wavelength discrimination by means of two distinct opsins, each with its own peak sensitivity, which work in an opponent fashion (Neitz and Neitz, 2011), we are unable to determine the ability of these double cones to provide such discrimination, as only the stronger opsin sensitivity was reported by Hofmann et al. (2009).

Our discovery of correlated evolution of visual sensitivity and color pattern is of particular interest for several reasons. First, this suggests a functional connection between visual sensitivity and color pattern, a novel finding in Lake Malawi cichlids (Dalton 


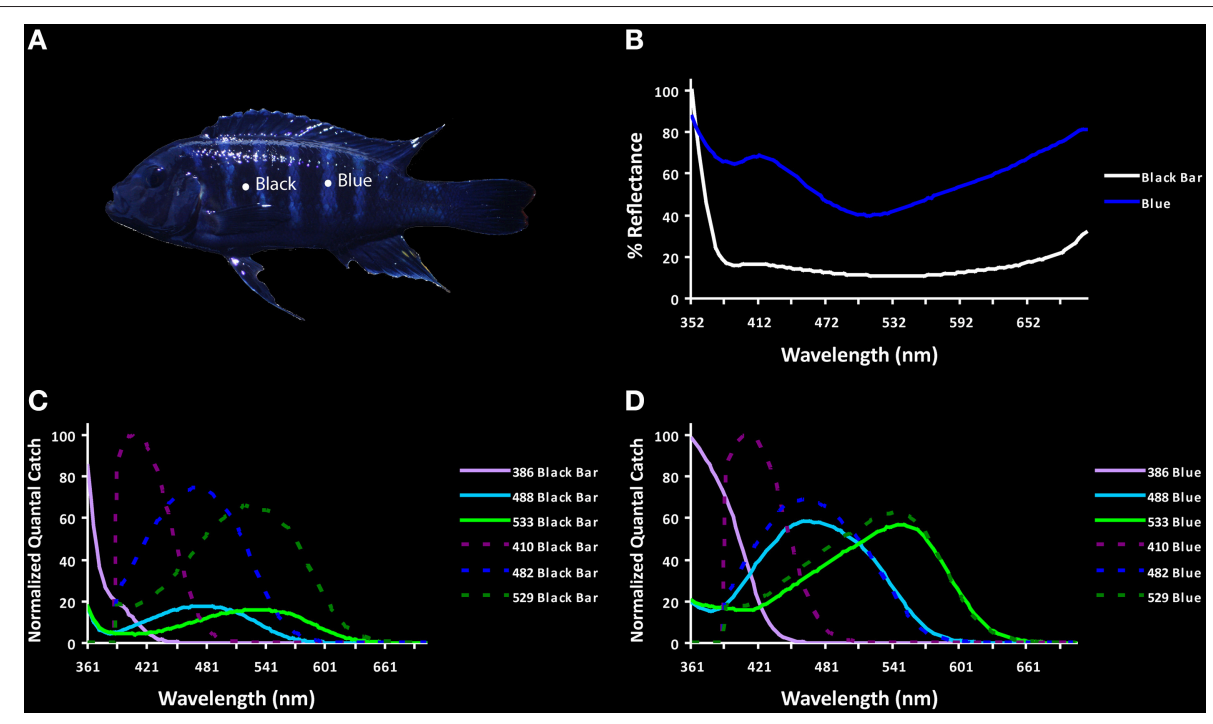

FIGURE 6 | Metriaclima zebra. Each figure in Figures 6-11 is arranged in the same fashion. There are four panels in each figure: (A) is a photograph of the fish under full-spectrum lighting (including UV illumination), indicating two points at which reflectances were measured; (B) illustrates the reflected wavelengths at the points indicated in (A); (C,D) are comparisons of the quantal catches of the reflectances by the photoreceptors found in two different classes of Malawi cichlid retinae: UV sensitive (solid lines) and non-UV sensitive (dashed lines). Photopigment sensitivities were taken from Hofmann et al. (2009).

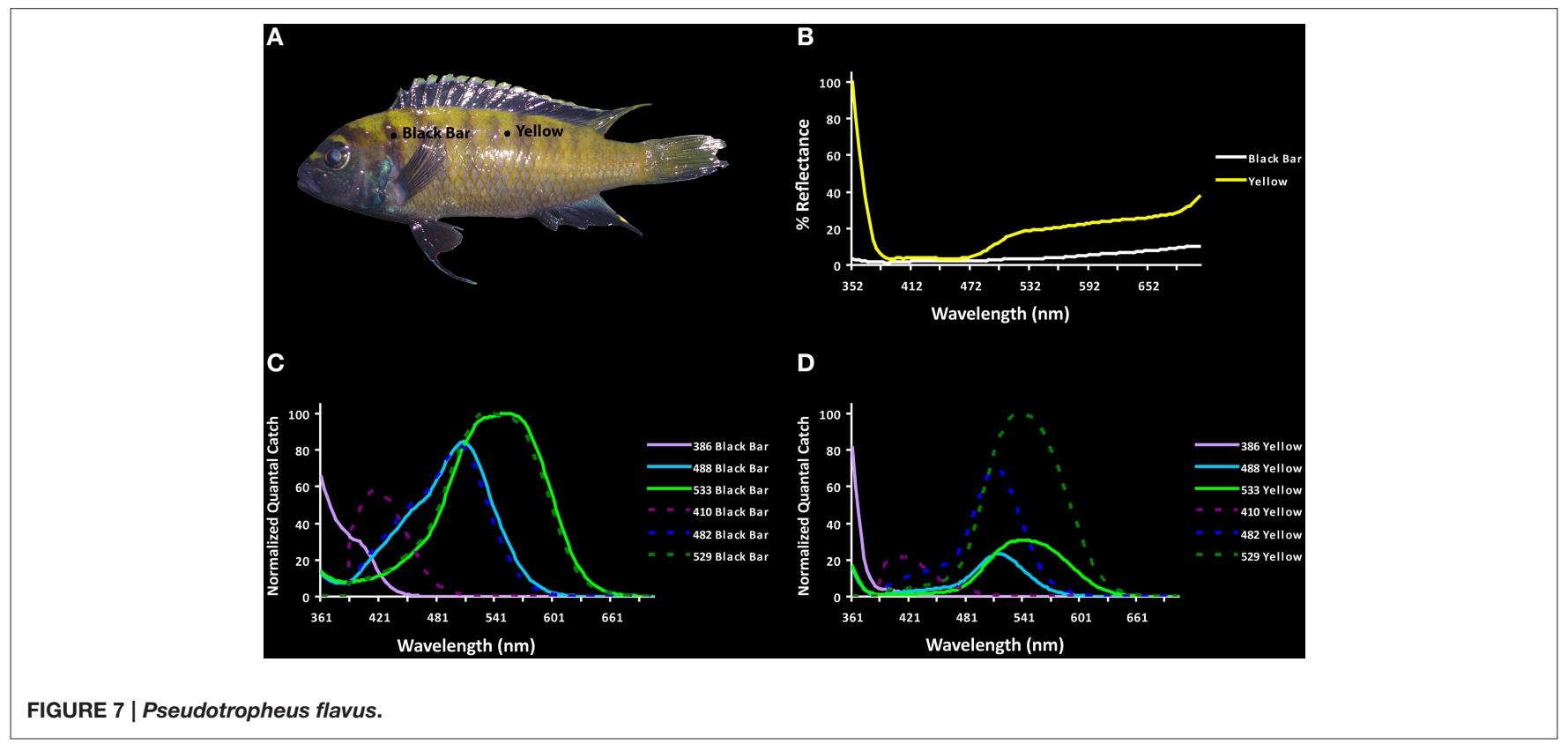

et al., 2010). Secondly, in order for a loss of UV sensitivity to occur, it appears that a horizontally-striped color pattern must evolve first. This indicates that visual sensitivity responds to the change in color pattern, suggesting that visual sensitivity may adapt to maximize the efficacy of visual communication via color patterns. Correspondingly, the values of $\lambda$ for both visual sensitivity and color pattern were less than one, suggesting that traits are less similar among closely-related species than expected; thus, our analysis explains the diversity in visual sensitivity and color pattern seen within the Lake Malawi cichlid flock.
Finally, and perhaps most interestingly, the direction of this evolution, from a barred, UV-sensitive ancestor, to a striped, nonUV-sensitive descendant, is different from what had previously been found in Lake Malawi cichlids. In a recently published phylogenetic analysis of visual sensitivity in African cichlids (O'Quin et al., 2010) found that the ancestor of Lake Malawi cichlids most likely had to have a long-wavelength sensitive visual system, and likely lacked UV sensitivity. This difference between our result and theirs could be partially explained by the different types of data we used; O'Quin et al. (2010) used 


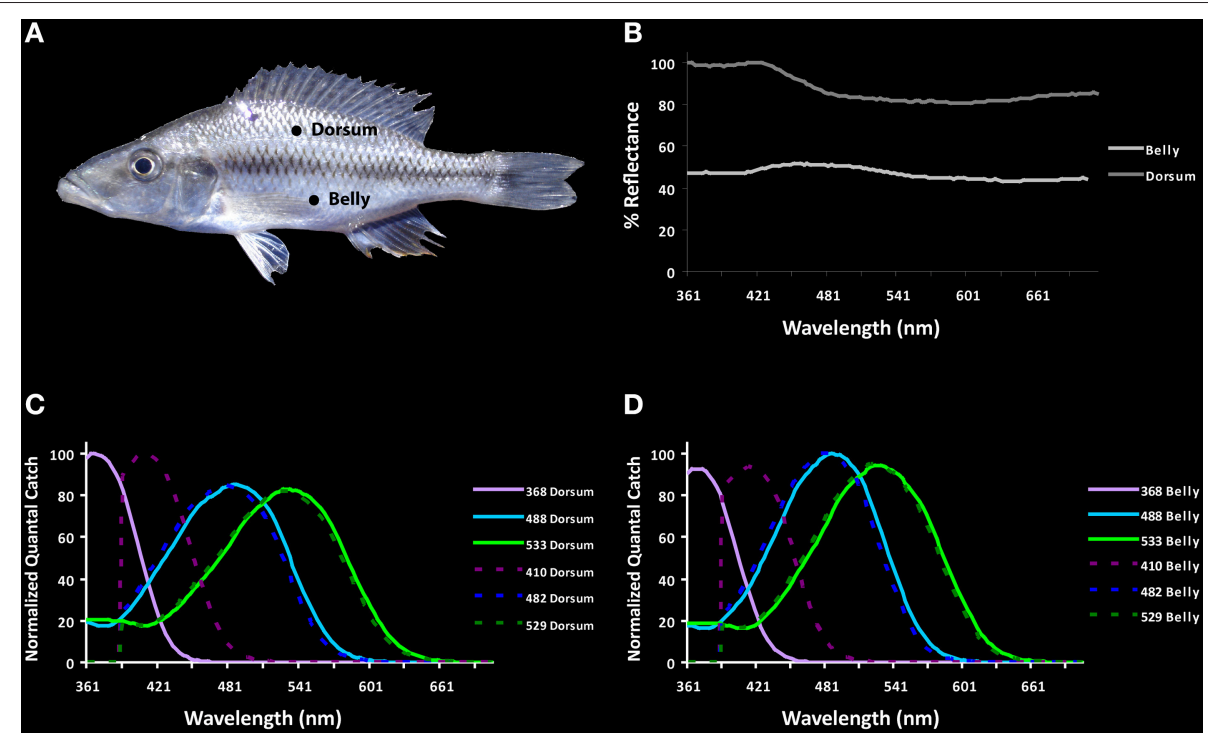

FIGURE 8 | Dimidiochromis compressiceps.

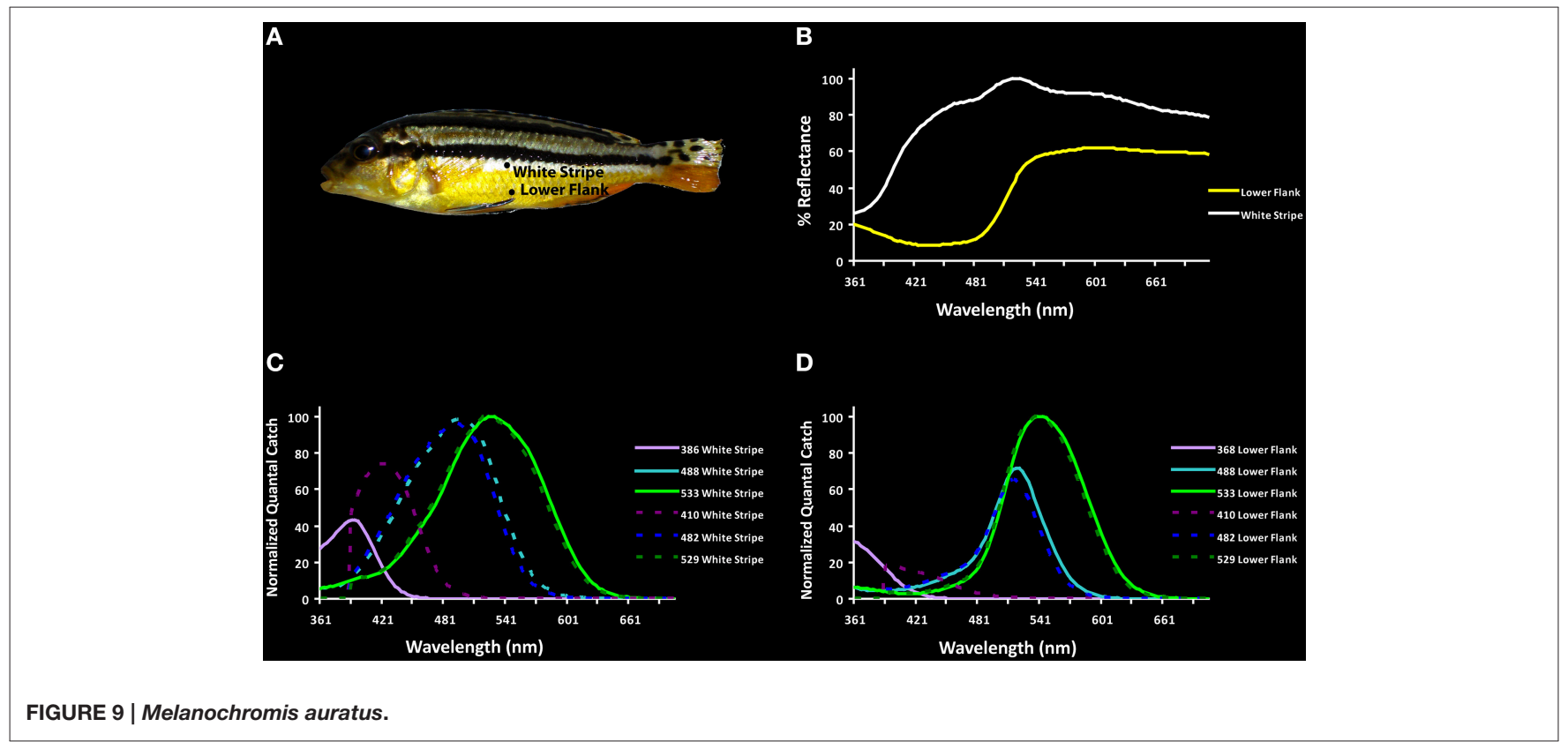

continuous data, while we used categorical, but a recent paper by Hunt and Peichl (2014) provides support for our findings. While losses of UV sensitivity throughout evolutionary and phylogenetic transitions are fairly common, the evolution of UV sensitivity from non-UV-sensitive ancestors is quite rare; only within the birds has UV sensitivity reappeared once lost (Ödeen and Håstad, 2013; Hunt and Peichl, 2014). Thus, the evolution of UV-sensitive cichlids from a non-UV ancestor is rather unlikely.

In an interesting recent study, York et al. (2015) also found that opsin evolution is likely related to the evolution of a different sexually-selected characteristic in Lake Malawi cichlids. Among the sand-dwelling cichlids, some species of which were included in the present analyses, males build bowers of sand that are used to attract females. These authors found that, between species that build the two fundamental types of bower, "pits" and "castles," pit-building species had a longer-shifted SWS photoreceptor sensitivity, while castle builders had a shorter-shifted SWS photoreceptor, often with UV sensitivity. Further, there were no differences between pit- and castle building species in the sensitivities of the longer-shifted opsins found in the double cones of these fishes. York et al. (2015) suspect that this may be 

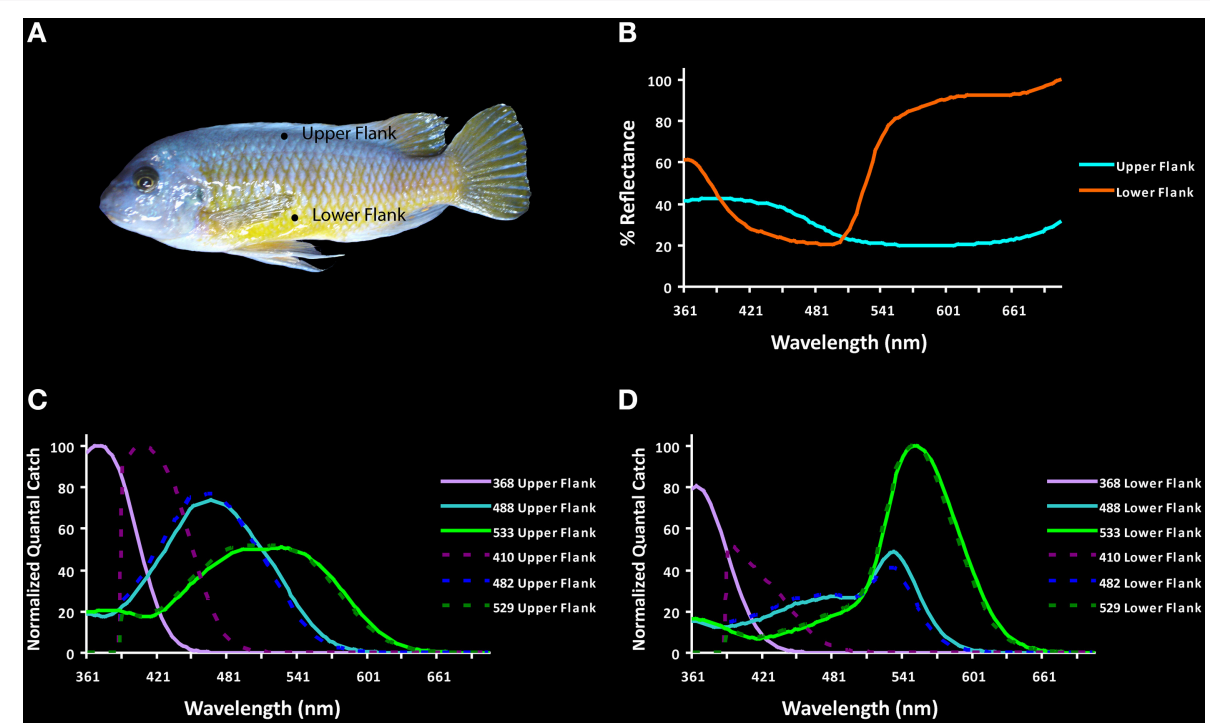

FIGURE 10 | Labeotropheus c.f. fuelleborni "Katale."
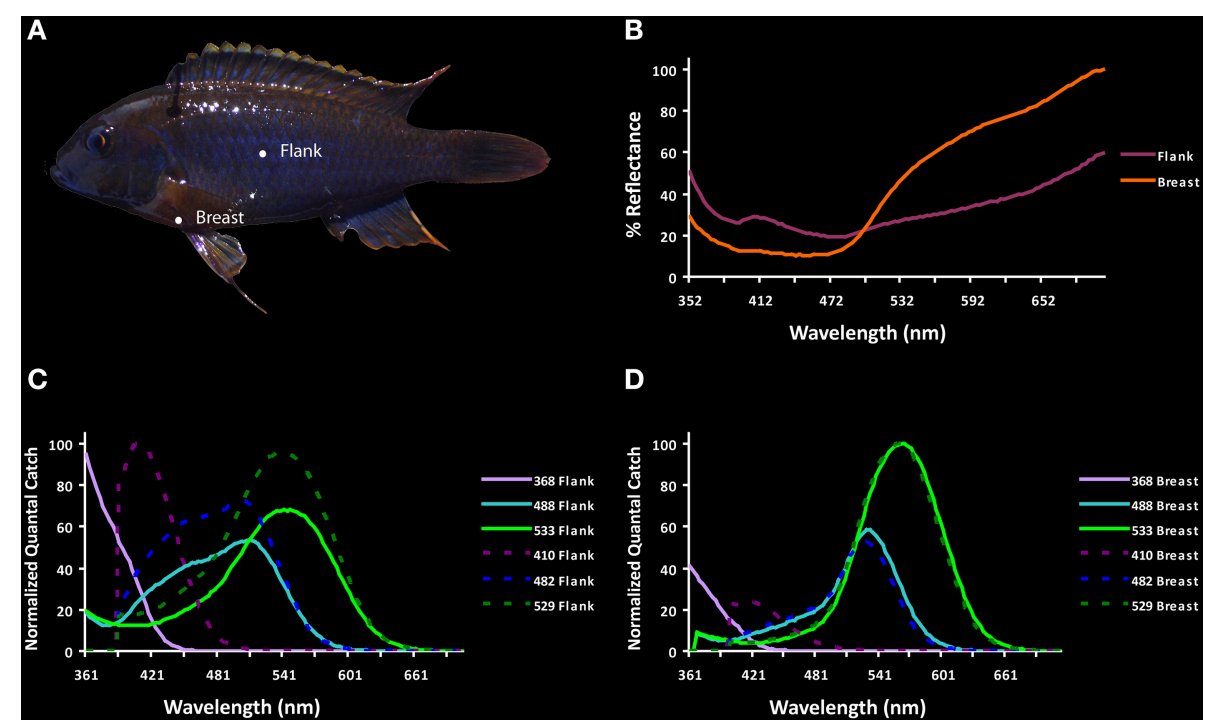

D

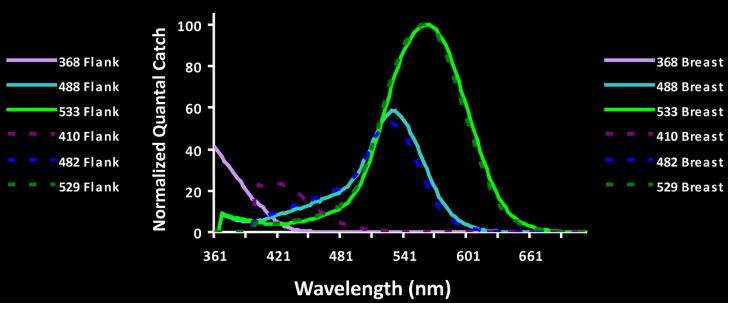

FIGURE 11 | lodotropheus sprengerae.

due at least in part to depth, as pit bowers are more common in deeper waters and castles more common in shallow. While these authors did not perform a phylogenetically-corrected analysis between opsin sensitivities and bower type, it is nonetheless interesting that they recovered a similar relationship between SWS opsin sensitivity and the form of a sexually-selected signal in Lake Malawi cichlids (York et al., 2015); it would be further tantalizing to determine whether or not evolutionary changes in SWS sensitivity follow innovations in the shape of bowers in the sand-dwelling Malawian cichlids, similar to how we have found that a loss of UV sensitivity follows the loss of a vertically-barred color pattern.
The results presented here are consistent with the hypothesis that stripes and bars represent "public" and "private" information, respectively, and that barred and solid-patterned species maintain this privacy via a UV-sensitive SWS photoreceptor. UV sensitivity could maintain or enhance color contrast among color pattern elements, or could even allow for "private" communication by changing the way a color pattern is perceived. Species that lack UV sensitivity, on the other hand, are likely not able to clearly perceive the fundamental message communicated via barred and "solid" patterns. Further, since the horizontal stripes found in non-UV species likely represent a form of camouflage, such a pattern 


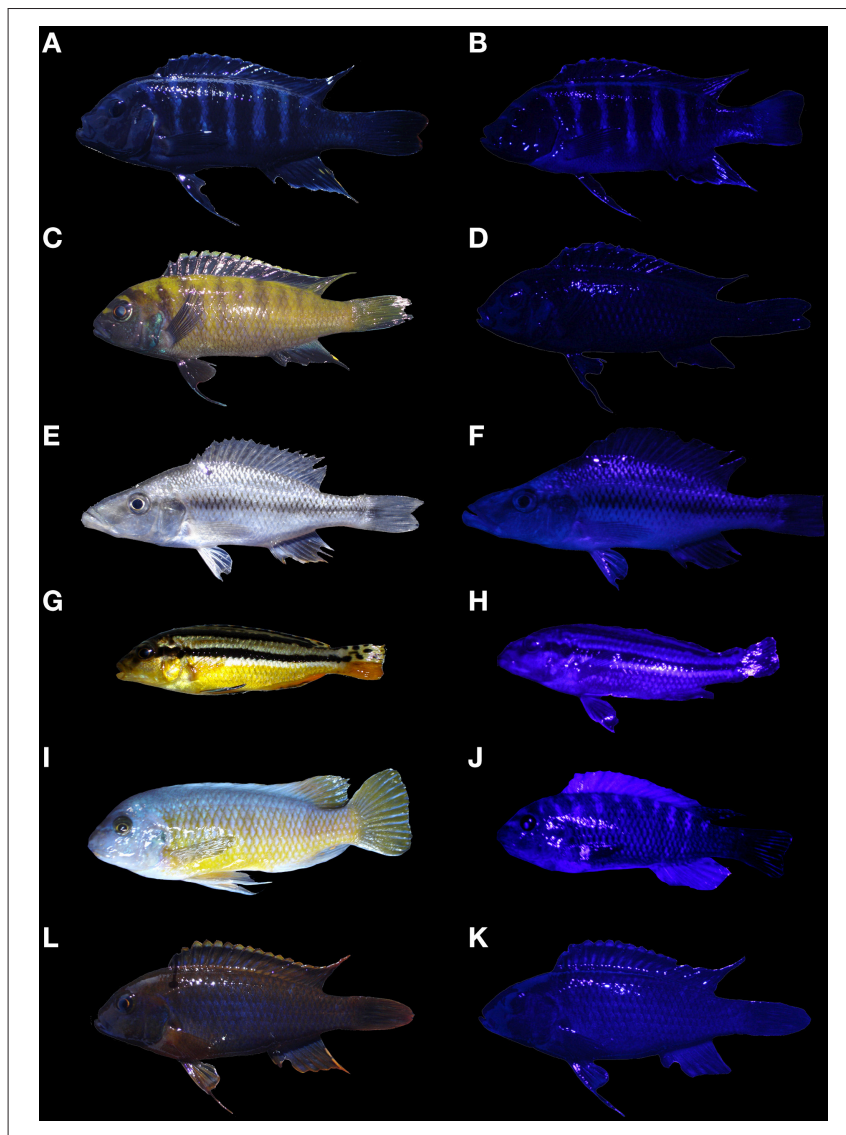

FIGURE 12 | Lake Malawi cichlid color patterns under full-spectrum light and UV lighting. (A,B), Metriaclima zebra; (C,D), Pseudotropheus flavus; (E,F), Dimidiochromi scompressiceps; (G,H), Melanochromis auratus; $\mathbf{( I , J ) , ~ L a b e o t r o p h e u s ~ c . f ~ f u e l l e b o r n i ~ " K a t a l e ; " ~ ( K , L ) , ~ l o d o t r o p h e u s ~ s p r e n g e r a e . ~}$ Species displaying different hues were selected to emphasize that the fundamental pattern, and the messages encoded therein, are independent of hue. In the barred and solid species, notice how UV lighting emphasizes the contrast between bars and background (B, e.g.,) or among color pattern elements (J, e.g.,), sometimes revealing hidden or de-emphasized contrasts (the highly reflective bars and the contrast between peduncle and flank in $\mathbf{J}$ ). In the striped species $(\mathbf{E}-\mathbf{H})$, the balance among elements stays the same whether the illumination is full-spectrum or UV, thus suggesting that this pattern is meant to be visible and understood by all visual systems.

would need to be clearly perceived by all species; if the patterns appeared differently to UV-sensitive and UV-insensitive fishes, concealment would be compromised. These results, then, suggest that the overall purpose for animal color patterns consisting of patches of alternating hues, as opposed to patches of alternating brightness, is to provide either "private" signals visible to only certain species (e.g., nuptial color patterns; Endler, 1992); or "public" information, like camouflage or advertisement of services (e.g., cleaner fishes), visible to species of varying visual sensitivities.

Our results also offer an explanation why Dalton et al. (2010) found no close concordance between photoreceptor sensitivity and cichlid body reflectance, as would be predicted if sensory drive processes were responsible for male nuptial coloration
(Endler, 1992). Lake Malawi cichlids with a barred color pattern display a wide range of colors across the spectrum including blue (e.g., Metriaclima zebra), yellow (e.g., Pseudotropheus flavus), and brown bars (e.g., P. crabro, P. livingstonii, and P. lombardoi). The sensory drive hypothesis predicts that species with blue bars should be most sensitive to short wavelengths, while those with yellow or brown bars should be most sensitive to longer wavelengths. The results presented here indicate otherwise; barred cichlids, no matter the colors present in their patterns, have short-shifted visual sensitivities. This calls into question the role that sensory drive processes, based on color alone, may have played in the evolution of male nuptial coloration in the Lake Malawi cichlids. For example, female Labeotropheus c.f. fuelleborni "Katale" prefer sympatric, conspecific males with high contrast among color pattern elements (Pauers et al., 2004). Actual reflected wavelengths may not matter as long as contrast is maintained, and the contrast defines a distinct pattern that is perceptible by the fishes themselves (Pauers, 2011). This resolves a long-standing conundrum surrounding Lake Malawi cichlids: How is species recognition maintained in these fishes when the putative major cue for mate recognition, male nuptial coloration, is limited to the same color palette across species, and when photopigment sensitivity is also similar among species? Color may certainly play a role, but both the arrangement and contrast of color pattern elements may be just as important.

\section{AUTHOR CONTRIBUTIONS}

MP conceived the study described herein, with significant input from JN. MP gathered the data and performed the statistical analyses. SJ constructed the phylogenies used in all analyses, and wrote the phylogenetic methods. MP and JN discussed the results and outlined the manuscript. MP wrote the manuscript, with editorial input from JK, SJ, and JN. JK contributed revisions to several drafts and helped construct and provided the interpretations for Figures 6-11. All authors read and approved the final draft for submission.

\section{FUNDING}

This work was supported by funds granted to MP from the Orth Ichthyology Research Fund at the Milwaukee Public Museum, as well as from the UW Colleges (Department of Biological Sciences Professional Development Fund, and a Summer Research Grant). This work also benefitted from a donation of aquarium equipment by Aqueon, Inc. (Franklin, WI, USA). The work was also supported by $\mathrm{NIH}$ P30EY001730.

\section{ACKNOWLEDGMENTS}

Jeffrey S. McKinnon East Carolina University) and Joshua M. Kapfer (University of Wisconsin-Whitewater) were instrumental in locating and loaning the spectrophotometry equipment used in this study. UW Colleges Vice Chancellor Joe Foy helped to secure lab space for MP. Emmanuel Paradis provided much 
needed advice and instruction for using his ape software package. Scott Greenwald (University of Washington) commented on numerous drafts of this article. Su Borkin, Ellen Censky,

\section{REFERENCES}

Baerends, G. P., and Baerends-van Roon, J. M. (1950). An introduction to the study of the ethology of the cichlid fishes. Behav. Suppl. 1, 1-242.

Browman, H. I., Novales-Flamarique, I., and Hawryshyn, C. W. (1994). Ultraviolet photoreception contributes to prey search behavior in two species of zooplanktivorous fishes. J. Exp. Biol. 186, 187-198.

Castresana, J. (2000). Selection of conserved blocks from multiple alignments for their use in phylogenetic analysis. Mol. Biol. Evol. 17, 540-552. doi: 10.1093/oxfordjournals.molbev.a026334

Cheney, K. L., and Marshall, N. J. (2009). Mimicry in coral reef fish: how accurate is this deception in terms of color and luminance? Behav. Ecol. 20, 459-468. doi: 10.1093/beheco/arp017

Côté, I. M., and Cheney, K. L. (2005). Choosing when to be a cleaner-fish mimic. Nature 433, 211-212. doi: 10.1038/433211a

Cummings, M. E., Rosenthal, G. G., and Ryan, M. J. (2003). A private ultraviolet channel in visual communication. Proc. Roy. Soc. Lond. (B) 270, 897-904. doi: 10.1098/rspb.2003.2334

Dalton, B. E., Cronin, T. W., Marshall, N. J., and Carleton, K. L. (2010). The fish eye view: are cichlids conspicuous? J. Exp. Biol. 213, 2243-2255. doi: $10.1242 / \mathrm{jeb} .037671$

Endler, J. A. (1978). "A predator's view of animal color patterns," in Evolutionary Biology, Vol. 11, ed M. K. Hecht (New York, NY: Springer US), 319-364.

Endler, J. A. (1990). On the measurement and classification of colour in studies of animal colour patterns. Biol. J. Linn. Soc. 41, 315-352. doi: 10.1111/j.10958312.1990.tb00839.x

Endler, J. A. (1991). Variation in the appearance of guppy color patterns to guppies and their predators under different visual conditions. Vis. Res. 31, 587-608. doi: 10.1016/0042-6989(91)90109-I

Endler, J. A. (1992). Signals, signal conditions, and the direction of evolution. Am. Nat. 139(Suppl.), s125-s153. doi: 10.1086/285308

Endler, J. A. (1993). The color of light in forests and its implications. Ecol. Monog. 63, 1-27. doi: 10.2307/2937121

Endler, J. A., and Mielke, P. W. Jr. (2005). Comparing entire colour patterns as birds see them. Biol. J. Linn. Soc. 86, 405-431. doi: 10.1111/j.10958312.2005.00540.x

Fernald, R. D. (2006). Casting a genetic light on the evolution of eyes. Science 313, 1914-1918. doi: 10.1126/science.1127889

Harmon, L., Weir, J., Brock, C., Glor, R., Challenger, W., Hunt, G., et al. (2014). geiger: Analysis of Evolutionary Diversification. Available online at: https://cran. r-project.org/web/packages/geiger/geiger.pdf

Hofmann, C. M., O’Quin, K. E., Marshall, N. J., Cronin, T. W., Seehausen, O., and Carleton, K. L. (2009). The eyes have it: regulatory and structural changes both underlie cichlid visual pigment diversity. PLoS Biol. 7:e1000266. doi: 10.1371/journal.pbio.1000266

Hunt, D. M., and Peichl, L. (2014). S cones: evolution, retinal distribution, development, and spectral sensitivity. Vis. Neurosci. 31, 115-138. doi: $10.1017 / \mathrm{S} 0952523813000242$

Jordan, R. C., Howe, D. V., Juanes, F., Stauffer, J. R. Jr., and Loew, E. R. (2004b). The role of ultraviolet radiation in foraging in a group of Lake Malawi cichlids. Afr. J. Ecol. 42, 228-231. doi: 10.1111/j.1365-2028.2004.00494.x

Jordan, R. C., Kellogg, K. A., Juanes, F., Howe, D., Stauffer, J. R. Jr., Losey, G., et al. (2004a). Ultraviolet reflectivity in three species of Lake Malawi rockdwelling cichlids. J. Fish Biol. 65, 876-882. doi: 10.1111/j.0022-1112.2004. 00483.x

Kelley, J. L., Fitzpatrick, J. L., and Merilaita, S. (2013). Spots and stripes: ecology and colour pattern evolution in butterflyfishes. Proc. Roy. Soc. Lond. B. 280:20122730. doi: 10.1098/rspb.2012.2730

Kenward, B., Wachtmeister, C.-A., Ghirlanda, S., and Enquist, M. (2004). Spots and stripes: the evolution of repetition in visual signal form. J. Theor. Biol. 230, 407-419. doi: 10.1016/j.jtbi.2004.06.008 and Robert Henderson (Milwaukee Public Museum) provided logistical support and time to MP during preparation of this article.
Kodric-Brown, A., and Johnson, S. C. (2002). Ultraviolet reflectance patterns of male guppies enhance their attractiveness to females. Anim. Behav. 63, 391-396. doi: 10.1006/anbe.2001.1917

Konings, A. (2007). Malawi Cichlids in their Natural Habitat, 4th Edn. El Paso, TX: Cichlid Press.

Konings, A. F., and Stauffer, J. R. Jr. (2012). Review of the Lake Malawi genus Melanochromis (Teleostei: Cichlidae) with a description of a new species. Zootaxa 3258, 1-27.

Land, M. F., and Nilsson, D.-E. (2002). Animal Eyes. New York, NY: Oxford University Press.

Losey, G. S. (2003). Crypsis and communication functions of UV-visible coloration in two coral reef damselfish, Dascyllus aruanus and D. reticulatus. Anim. Behav. 66, 299-307. doi: 10.1006/anbe.2003.2214

Losey, G. S., Cronin, T. W., Goldsmith, T. H., Hyde, D., Marshall, N. J., and McFarland, W. N. (1999). The UV visual world of fishes: a review. J. Fish Biol. 54, 921-943. doi: 10.1111/j.1095-8649.1999.tb00848.x

Losey, G. S., McFarland, W. N., Loew, E. R., Zamzow, J. P., Nelson, P. A., and Marshall, N. J. (2003). Visual biology of Hawaiian coral reef fishes. I. Ocular transmission and visual pigments. Copeia 2003, 433-454. doi: 10.1643/01-053

Marshall, N. J., Jennings, K., McFarland, W. N., Loew, E. R., and Losey, G. S. (2003). Visual biology of Hawaiian coral reef fishes. III. Environmental light and an integrated approach to the ecology of reef fish vision. Copeia 2003, 467-480. doi: 10.1643/01-056

Meade, A., and Pagel, M. (2014). BayesTraits 2.0. Available online at: http://www. evolution.rdg.ac.uk/BayesTraitsV2.0Files/TraitsV2Manual.pdf

Milner, A. D., and Goodale, M. A. (1995). The Visual Brain in Action. New York, NY: Oxford University Press.

Neitz, J., and Neitz, M. (2011). The genetics of normal and defective color vision. Vis. Res. 51, 633-651. doi: 10.1016/j.visres.2010.12.002

Notredame, C., Higgins, D. G., and Heringa, J. (2000). T-Coffee: a novel method for multiple sequence alignments. J. Mol. Biol. 302, 205-217. doi: 10.1006/jmbi.2000.4042

Ödeen, A., and Håstad, O. (2013). The phylogenetic distribution of ultraviolet sensitivity in birds. BMC Evol. Biol. 13:36. doi: 10.1186/1471-2148-13-36

O'Quin, K. E., Hofmann, C. M., Hofmann, H. A., and Carleton, K. L. (2010). Parallel evolution of opsin gene expression in African cichlid fishes. Mol. Biol. Evol. 27, 2839-2854. doi: 10.1093/molbev/msq171

Pagel, M. (1999). The maximum likelihood approach to reconstructing ancestral character states of discrete characters on phylogenies. Syst. Biol. 48, 612-622. doi: 10.1080/106351599260184

Paradis, E., Blomberg, S., Bolker, B., Claude, J., Cuong, H. S., Desper, R., et al. (2015). ape: Analyses of Phylogenetics and Evolution. Available online at: https:// cran.r-project.org/web/packages/ape/ape.pdf

Parry, J. W. L., Carleton, K. L., Spady, T. C., Carboo, A., Hunt, D. M., and Bowmaker, J. K. (2005). Mix and match color vision: tuning spectral sensitivity by differential opsin gene expression in Lake Malawi cichlids. Curr. Biol. 15, 1734-1739. doi: 10.1016/j.cub.2005.08.010

Pauers, M. J. (2011). One fish, two fish, red fish, blue fish: geography, ecology, sympatry, and male coloration in the Lake Malawi cichlid genus Labeotropheus (Perciformes: Cichlidae). Int. J. Evol. Biol. 2011:575469. doi: 10.4061/2011/ 575469

Pauers, M. J., Kapfer, J. M., Doehler, K., Lee, J. T., and Berg, C. S. (2012). Gross colour pattern is used to distinguish between opponents during aggressive encounters in a Lake Malawi cichlid. Ecol. Freshw. Fish 21, 34-41. doi: 10.1111/j.1600-0633.2011.00520.x

Pauers, M. J., McKinnon, J. S., and Ehlinger, T. J. (2004). Directional sexual selection on chroma and within-pattern contrast in Labeotropheus fuelleborni. Proc. Biol. Sci. 271, S444-S447. doi: 10.1098/rsbl.2004.0215

Ribbink, A. J., Marsh, B. A., Marsh, A. C., Ribbink, A. C., and Sharp, B. J. (1983). A preliminary survey of the cichlid fishes of rocky habitats in Lake Malawi. S. Afr. J. Zool. 18, 149-310. doi: 10.1080/02541858.1983.11447831 
Ryan, M. J., and Rand, A. S. (1990). The sensory basis of sexual selection for complex calls in the tûngara frog, Physalaemus pustulosus (sexual selection for sensory exploitation). Evolution 44, 305-314. doi: 10.2307/2409409

Sabbah, S., Gray, S. M., Boss, E. S., Fraser, J. M., Zatha, R., and Hawryshyn, C. W. (2011). The underwater photic environment of Cape Maclear, Malawi: comparison between rock- and sand-bottom habitats and implications for cichlid fish vision. J. Exp. Biol. 214, 487-500. doi: 10.1242/jeb.051284

Seehausen, O., Mayhew, P. J., and van Alphen, J. J. M. (1999). Evolution of colour patterns in East African cichlid fish. J. Evol. Biol. 12, 514-534. doi: 10.1046/j.1420-9101.1999.00055.x

Seehausen, O., Terai, Y., Magalhaes, I. S., Carleton, K. L., Mrosso, H. D. J., Miyagi, R., et al. (2008). Speciation through sensory drive in cichlid fish. Nature 455, 620-627. doi: 10.1038/nature07285

Siebeck, U. E., Parker, A. N., Sprenger, D., Mäthger, L. M., and Wallis, G. (2010). A species of reef fish that uses ultraviolet patterns for covert face recognition. Curr. Biol. 20, 407-410. doi: 10.1016/j.cub.2009.12.047

Stamatikis, A. (2014). RAxML Version 8: a tool for phylogenetic analysis and post-analysis of large phylogenies. Bioinformatics 30, 1312-1313. doi: 10.1093/ bioinformatics/btu033 van Staaden, M. J., and Smith, A. R. (2011). Cutting the Gordian knot: complex signaling in African cichlids is more than multimodal. Curr. Zool. 57, $237-252$.

Voss, J. (1980). Colour Patterns in African Cichlids. Neptune, NJ: Tropical Fish Hobbyist.

York, R. A., Patel, C., Hulsey, C. D., Anoruo, O., Streelman, J. T., and Fernald, R. D. (2015). Evolution of bower building in Lake Malawi cichlid fish: phylogeny, morphology, and behavior. Front. Ecol. Evol. 3:18. doi: 10.3389/fevo.2015.00018

Conflict of Interest Statement: The authors declare that the research was conducted in the absence of any commercial or financial relationships that could be construed as a potential conflict of interest.

Copyright (C) 2016 Pauers, Kuchenbecker, Joneson and Neitz. This is an open-access article distributed under the terms of the Creative Commons Attribution License (CC $B Y)$. The use, distribution or reproduction in other forums is permitted, provided the original author(s) or licensor are credited and that the original publication in this journal is cited, in accordance with accepted academic practice. No use, distribution or reproduction is permitted which does not comply with these terms. 